\title{
Review
}

Julian Bender and Carla Schmidt*

\section{Mass spectrometry of membrane protein complexes}

https://doi.org/10.1515/hsz-2018-0443

Received November 29, 2018; accepted February 25, 2019; previously published online April 8, 2019

Abstract: Membrane proteins are key players in the cell. Due to their hydrophobic nature they require solubilising agents such as detergents or membrane mimetics during purification and, consequently, are challenging targets in structural biology. In addition, their natural lipid environment is crucial for their structure and function further hampering their analysis. Alternative approaches are therefore required when the analysis by conventional techniques proves difficult. In this review, we highlight the broad application of mass spectrometry (MS) for the characterisation of membrane proteins and their interactions with lipids. We show that MS unambiguously identifies the protein and lipid components of membrane protein complexes, unravels their three-dimensional arrangements and further provides clues of protein-lipid interactions.

Keywords: lipids; mass spectrometry; membrane proteins; protein interactions; protein-lipid interactions.

\section{Introduction}

Membrane proteins take central roles in living cells including, for instance, energy production, signal transmission and molecule transport. Accordingly, they are the targets of many present day's drugs (Overington et al., 2006) and have been, and still are, the focus of many structural studies. However, although $26 \%$ of the

\footnotetext{
*Corresponding author: Carla Schmidt, Interdisciplinary Research Center HALOmem, Charles Tanford Protein Centre, Martin Luther University Halle-Wittenberg, Institute for Biochemistry and Biotechnology, Kurt-Mothes-Str. 3a, D-06120 Halle, Germany, e-mail: carla.schmidt@biochemtech.uni-halle.de. https://orcid.org/0000-0001-9410-1424

Julian Bender: Interdisciplinary Research Center HALOmem, Charles Tanford Protein Centre, Martin Luther University Halle-Wittenberg, Institute for Biochemistry and Biotechnology, Kurt-Mothes-Str. 3a, D-06120 Halle, Germany. https://orcid.org/0000-0003-3316-9999
}

human genes encode for membrane proteins (Fagerberg et al., 2010), they only represent $2 \%$ of all available protein structures in the protein data bank (www.rcsb.org). This might be partially attributed to the special conditions required to produce and purify membrane proteins and their complexes.

In addition, membrane proteins represent challenging targets for classical structural techniques such as X-ray crystallography or nuclear magnetic resonance (NMR) spectroscopy which require a large amount of pure and homogeneous sample. Nonetheless, despite the challenges of protein production, most of the available structures of membrane proteins originate from these techniques. In the cases where sample amounts are low or the sample is not homogeneous, mass spectrometry (MS) contributes a considerable amount of information on the protein identity, associated lipids, protein and lipid stoichiometries as well as protein and protein-lipid interactions. In the following, we will summarise recent developments in MS of membrane proteins and define its position in the field of structural biology.

\section{Expression and solubilisation of membrane proteins}

For structural analysis, proteins are recombinantly expressed if they cannot be extracted in large quantities from their natural sources or if mutations or affinity tags have to be introduced. In the natural environment of the cell, membrane proteins are not synthesised into the cytosol but rather require transport to their final destinations, i.e. the respective membranes. This process is in most cases mediated by a targeting signal sequence (Schnell and Hebert, 2003). Insertion into the target membrane, therefore, strongly depends on the presence of the corresponding translocation machinery; for instance, the prokaryotic SecYEG or BAM complexes (Papanikou et al., 2007; Knowles et al., 2009). Consequently the targeting sequence of a recombinantly expressed protein needs to be adapted to the translocation system of the expression 
host. Choosing the right expression system always requires evaluating sample yield and quality. To achieve a high quality sample, a homologous or closely related expression system is preferred allowing correct folding of the protein. If the system is not amenable to genetic modification or if high yields are required heterologous, prokaryotic expression systems are usually chosen. The most commonly employed expression systems are Escherichia coli, Lactococcus lactis and Saccharomyces cerevisiae or Saccharomyces pombe as well as some insect or mammalian cells (Junge et al., 2008). Another promising tool is cell-free expression; a method that utilises purified transcription and translation machineries for direct production of proteins from a DNA template in a test tube (Nirenberg and Matthaei, 1961).

The hydrophobic core of the lipid environment of a membrane protein clearly has an impact on its structure and function. As the membrane composition strongly varies between the various expression systems (Opekarová and Tanner, 2003), its impact on the protein structure has to be assessed and optimised for each individual membrane protein. For example, bacterial membranes are lacking sterols, sphingolipids and lipids with polyunsaturated fatty acid chains, all of which are common to eukaryotic membranes. Furthermore, eukaryotic post-translational modifications such as phosphorylation, prenylation or glycosylation are usually not available in bacterial expression systems (Junge et al., 2008). All these factors contribute to the difficulties which have to be overcome when expressing membrane proteins.

Nonetheless, structural analysis of membrane proteins requires, in all cases, their extraction from the membrane. This is usually achieved by using detergents which form hydrophilic micelles around the hydrophobic part of the protein thereby facilitating solubilisation. The choice of the right detergent for extraction is crucial for retaining the active and stable form of the protein. While ionic detergents have good solubilisation properties, they are often denaturing and only applicable to very stable membrane proteins or protein complexes (Seddon et al., 2004). Milder alternatives include non-ionic detergents such as $n$-dodecyl- $\beta$ - $d$ maltopyranoside (DDM) or bile acid salts like cholate. Due to the unpredictable effects of detergents on membrane protein structure and function, detergent screening is usually performed for every individual protein. A recently published protocol allows detergent exchange during electrospray desorption of surface-deposited membrane proteins. Monitoring the ion signal in the mass spectrometer, therefore allows addressing the protein state directly and simplifies high-throughput detergent screening (Ambrose et al., 2017).

For structural or functional analysis, the proteins are transferred from the detergent micelle into synthetic membrane mimetics. A typical example are so-called nanodiscs (Bayburt and Sligar, 2009) which represent planar lipid bilayers. Bicelles, on the other hand, employ an amphipathic lipid with micelle-like properties (Sanders and Prosser, 1998). An alternative approach to solubilisation of the proteins from the membrane is the expression in a cell-free system containing with nanodiscs (Henrich et al., 2017a). In this way, functional rhodopsin-2 was transferred into a native-like lipid bilayer without the need of a specific insertion system. Despite this promising example, co-translational insertion still remains poorly understood and might not be applicable to membrane proteins in general.

\section{The lipid environment of membrane proteins}

In general, lipids fulfil three main functions in living organisms: (i) they store energy and are caches for fatty acids and sterol components, (ii) they provide secondary messengers in signalling processes, and (iii) they form lipid bilayers of biological membranes (Meer et al., 2008). Biological membranes are functionally and structurally important. For instance, they form membrane-enclosed compartments that insulate cellular reactions and thereby increase their efficiency. Biological membranes are semipermeable, i.e. they separate the cytosol or organelle matrices from their surrounding environment while allowing exchange of material or information. Transport of material and information is mostly mediated by the proteins that reside in the membranes, however, this can also be accomplished by vesicle budding or fusion.

Polar phospholipids, sphingolipids and non-polar sterols are the main constituents of eukaryotic membranes (Figure 1). Of these, phospholipids and sphingolipids comprise 60 and 10 mol\% of most mammalian membranes, respectively, while non-polar sterols comprise a range of $0.1-40 \mathrm{~mol} \%$, depending on the subcellular localisation of the membranes (Han and Gross, 2005). Structurally, phospholipids share a glycerol backbone to which two fatty acyl chains and one polar head group are connected while sphingolipids are based on ceramide, i.e. a sphingosine backbone with one ester-linked fatty acid chain (see Figure 1 for details). Most non-polar sterols are represented by cholesterol derivatives. Even though the 


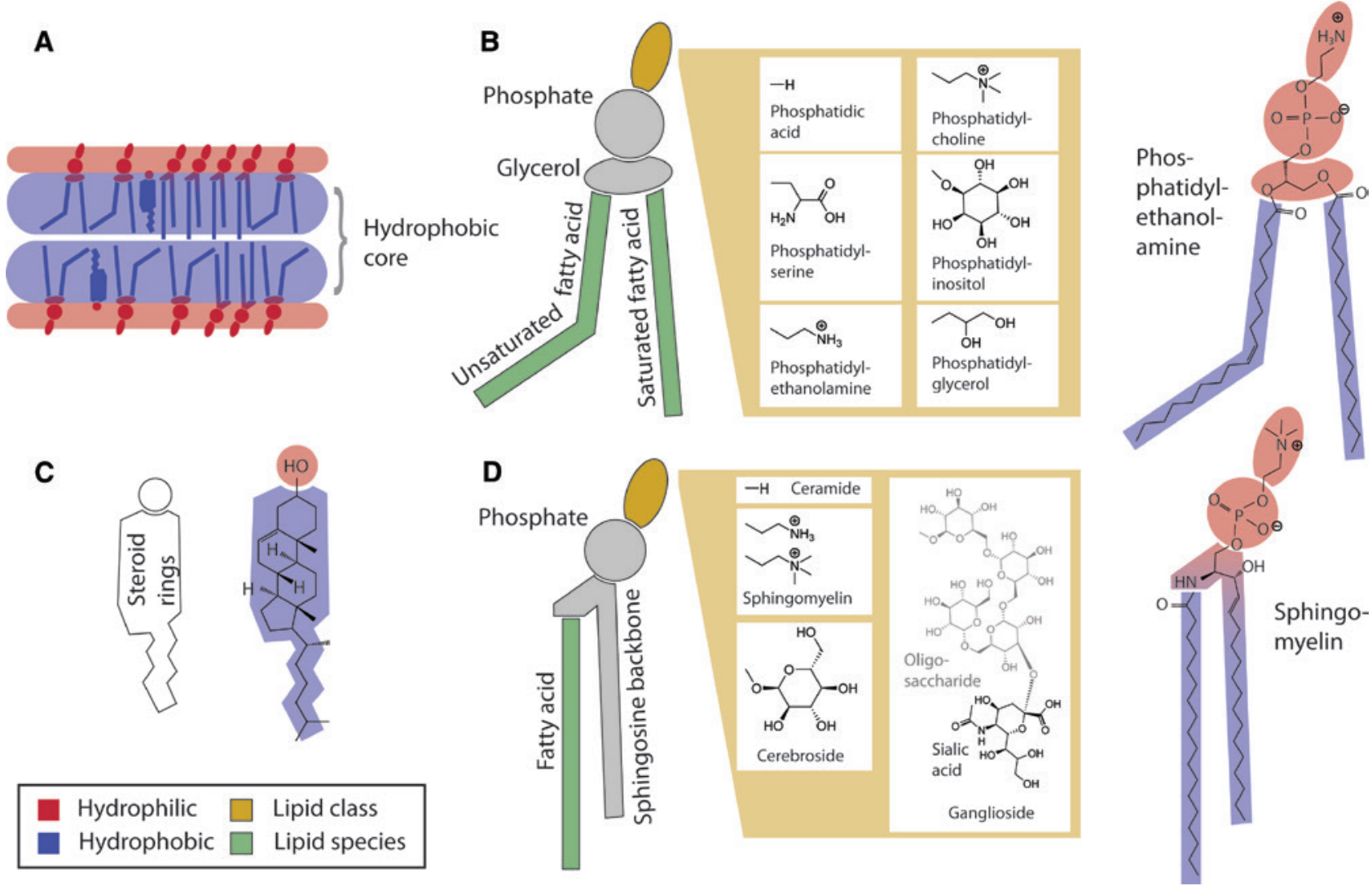

Figure 1: Common lipids in eukaryotic membranes.

(A) General structure of a lipid bilayer. (B) Schematic structure of glycerophospholipids. The head group defines the type of glycerophospholipid. Phosphatidylethanolamine is shown as an example. (C) Schematic of sterols. Cholesterol is shown as an example. (D) Schematic structure of sphingolipids. The head group defines the type of sphingolipid. Sphingomyelin is shown as an example.

Polar (red) and nonpolar (blue) chemical groups are color-coded. Chemical groups differing between lipid classes (yellow) and between lipid species (green) of the same lipid type are indicated.

building blocks of membrane lipids are rather simple, the complexity arising from their different combinations is enormous. A total of $9000-10000$ lipid species has been estimated (Meer et al., 2008; Yetukuri et al., 2008). However, several lipid classes are exclusive to an organism thereby reducing the total lipid complexity for single species.

The lipid composition of a biological membrane defines its biophysical properties. As an example, the fluidity of membranes is directly linked with saturation of the fatty acid components. Most biological lipids therefore contain at least one double bond in cis-configuration in the fatty acyl chain to maintain fluidity of the membrane at room temperature (Meer et al., 2008). Fluidity is further regulated by the presence of sterols which interpose between lipids with saturated fatty acid chains such as sphingolipids (Bigay and Antonny, 2012). The fatty acyl chains of sphingolipids are usually fully saturated or unsaturated in trans-configuration resulting in a narrow structure which induces tight packing mostly found in solid gels or lipid rafts (London, 2002). The lipid composition further affects membrane thickness (Sharpe et al., 2010), curvature (Cooke and Deserno, 2006; McMahon and Boucrot, 2015), protein-protein (Schafer et al., 2011; Milovanovic et al., 2015) and protein-lipid (Murray and Tamm, 2011; van den Bogaart et al., 2011) interactions. It is therefore not surprising that both, the membrane composition and the membrane's biophysical properties, have a direct impact on membrane-embedded proteins. They affect not only their localisation to a particular organelle but also directly tune their activity (Klose et al., 2013).

In summary, lipid diversity correlates with the architectural complexity of a cell or, in other words, a cell with complex cellular organelles shows a higher lipid diversity than simpler organised cells (Simons and Sampaio, 2011). As a consequence, complex cellular organisation results in increasing diversity of membrane proteins; each with its own, specific lipid environment. 


\section{Identification of membrane lipids}

As discussed above, the lipid composition is crucial for the membrane's properties and consequently for the protein's activity. The identification of lipid components in biological membranes is therefore of the utmost importance. The analysis of lipids usually starts with their extraction from the membrane. Traditionally, this is achieved by using a mixture of chloroform and methanol to dissolve the lipids from the membrane followed by an aqueous washing step to remove non-lipid contaminants (Folch et al., 1957; Bligh and Dyer, 1959). Lipid extraction was recently optimised for MS-based analysis employing methyl-tert-butyl ether which facilitates removal of nonsoluble contaminants (Matyash et al., 2008).

First attempts towards lipid identification in complex mixtures were made by thin-layer chromatography (for a detailed description see Fuchs et al., 2011). However, with the advancement of electrospray ionisation (ESI) MS, the field of lipidomics gained importance (Brugger et al., 1997). For lipid identification, lipid extracts are often analysed directly in the mass spectrometer without further separation ('shotgun' lipidomics). Missing separation of isobaric species (i.e. different lipid species with the same nominal mass) and ion suppression were adversely discussed for this approach, however, improvements in instrumentation made the analysis of complete lipidomes in shotgun experiments possible (Schwudke et al., 2011). In contrast to shotgun experiments, lipid species can also be separated by coupling a chromatography system with the mass spectrometer [liquid chromatography-mass spectrometry (LC-MS)]. However, while chromatographic separation minimises ion suppression caused by matrix effects and reduces sample complexity (Harkewicz and Dennis, 2011), the relative lipid concentrations are also reduced, and solubility problems have to be considered.
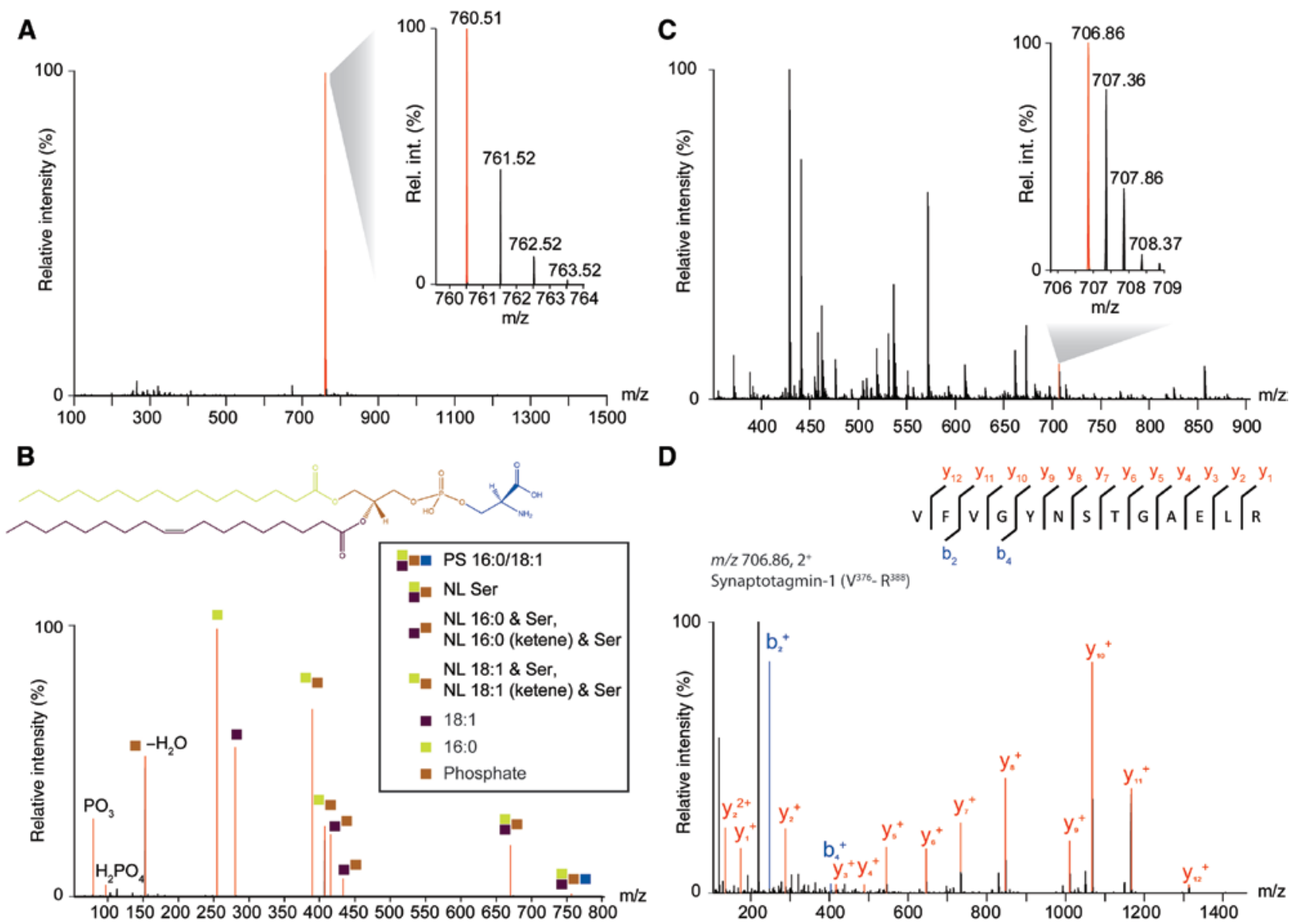

D
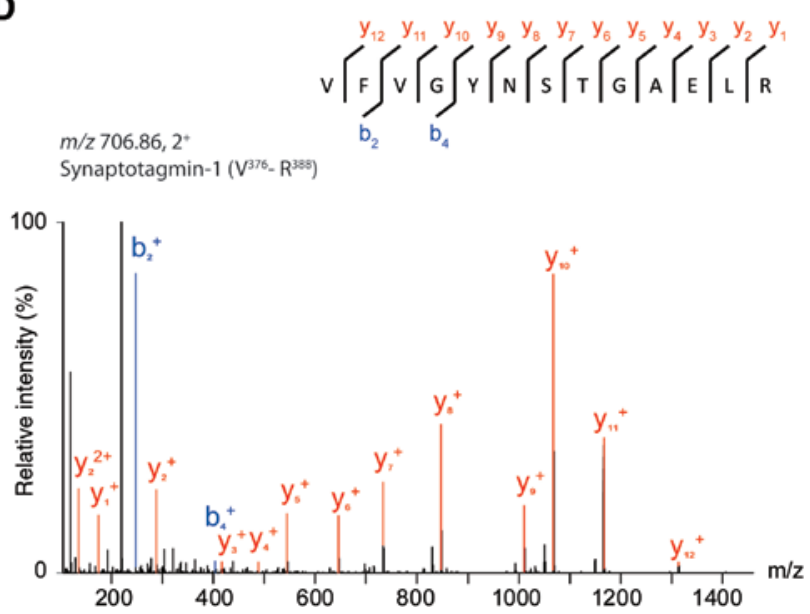

Figure 2: Lipid and protein identification.

(A) Mass spectrum of PS 16:0/18:1. The isotope distribution is magnified (inset). (B) Fragment spectrum of PS 16:0/18:1. Characteristic fragment ions are labelled. (C) Mass spectrum of a peptide mixture generated by tryptic hydrolysis. The selected peak for fragmentation is highlighted. (D) Fragment spectrum of a peptide derived from synaptotagmin-1. b- and y-ions are labelled. 
For confident lipid identification and for differentiation of isomers and isobars, precursor ions are usually selected during MS experiments and subsequently fragmented, e.g. by collision-induced dissociation (Figure 2A and $\mathrm{B})$. The resulting fragment ions provide information on the lipid class (for instance, by loss of specific head group fragments) and the fatty acid chains including length, number of double bonds and potential modifications (e.g. lyso-forms or oxidation) (Hsu and Turk, 2009). However, the sn-positions of the fatty acid chains as well as the position of double bonds in the chains cannot be deduced from conventional MS approaches. To gain this information, lipids are usually chemically modified (e.g. Paterno-Büchi reactions; Ma and Xia, 2014) or advanced MS techniques, such as ultraviolet photodissociation (UVPD) are employed (Williams et al., 2017).

One major goal in lipidomics is the simultaneous quantification of the identified lipids. This is usually achieved by comparing the peak area of a lipid with that of an internal standard spiked at known concentration (Brugger et al., 1997; Inloes et al., 2018). However, two difficulties complicate this approach: First, the isotopic envelope of a lipid in the mass spectrum overlaps with the isotopic envelopes of lipid species which differ in the number of double bonds; an issue which can be handled by taking the natural isotope distributions into account and calculating the theoretical peak envelope. Second, the ionisation efficiencies differ between the lipid classes and quantification has to be performed by using deuterated standard lipids for each lipid class (Shevchenko and Simons, 2010).

Recently, the range of lipidomics was extended for the identification of protein-associated lipids. For this, associated lipids were either extracted from the detergent-purified membrane proteins (Pyle et al., 2018) or the proteins were proteolytically hydrolysed and the generated peptide fraction was removed during LC separation leaving associated lipids for analysis (Zhou et al., 2011; Schmidt et al., 2013; Liko et al., 2016). In this way, information on the protein's direct environment including annular and tight-binding lipids can be obtained.

\section{Identification of membrane protein subunits}

The first step towards structural characterisation of a protein complex is to confirm the presence of all relevant protein subunits. The gold standard for protein identification is proteolytic hydrolysis of the proteins, either in solution or after separation by gel electrophoresis, followed by MS analysis (Shevchenko et al., 1996; Wilm et al., 1996). For soluble proteins, trypsin is the preferred endoproteinase due to several advantages: (i) it is commercially available at low costs, (ii) it specifically cleaves C-terminal of lysine and arginine residues thereby providing basic residues which facilitate the generation of positively charged ions during ESI, and (iii) the frequency of lysine and arginine residues results in peptides of a length well suited for MS analysis. Membrane proteins, in contrast, contain only a few tryptic cleavage sites and alternative proteases cleaving at hydrophobic amino acids residues are required. A prominent example is chymotrypsin which cleaves C-terminal of phenylalanine, tyrosine, leucine and tryptophan. A combination of proteases was also used to generate peptides of a suitable size and identify membrane protein subunits with reasonable confidence (Mazhab-Jafari et al., 2016). In addition, specialised protocols for membrane protein identification by MS have been developed (Wu and Yates, 2003). These protocols include, for instance, protein extraction from the membrane using high concentrations of acid, organic solvents or detergents. The implementation of acid-labile detergents such as RapiGest (Yu et al., 2003) further facilitated the hydrolysis of both soluble and membrane proteins.

After hydrolysis of the proteins, the peptides are usually separated by reversed-phase chromatography and subsequently analysed by tandem-MS (MS/MS). Here, mass-tocharge ratios of intact peptide ions are first acquired in MS experiments followed by the isolation and fragmentation of the most intense precursor ions in MS/MS experiments (Figure 2C and D). Fragmentation of the peptides occurs along the peptide backbone yielding fragment ions that differ in mass of the amino acids corresponding to the peptide sequence (Figure 2D). The mass-to-charge ratios of the precursor and fragment ions are then compared with the theoretical values of a database (Steen and Mann, 2004). This allows accurate identification of a protein from a complete proteome database of an organism or even from the complete UniProt repository (Griss et al., 2011).

In addition to identification of protein subunits, the described workflow allows identification of natural (post-translational) or artificial modifications. These are usually identified by a characteristic mass shift of specific amino acids in the peptide sequence. Furthermore, the peptide-based approach described here can be utilised for structural characterisation of (membrane) proteins as described in the following sections. 


\section{Describing the accessible surface area of membrane proteins}

The principle of protein surface labelling is the artificial modification of solvent-exposed amino acid residues providing information on the accessible surface of a protein or protein complex. As described above, introduced labels can be identified as a characteristic mass shift in the mass spectra. There are several strategies commonly followed for protein labelling: hydrogen-deuterium (H/D) exchange, hydroxyl radical footprinting (HRF), fast photochemical oxidation of proteins (FPOP) and covalent labelling.

$\mathrm{H} / \mathrm{D}$ exchange is based on the fact that protons in amine or hydroxyl groups of proteins exchange for deuterium in 'heavy' water $\left(\mathrm{D}_{2} \mathrm{O}\right)$ (Katta and Chait, 1993). In labelling experiments, water (solvent) accessible protons exchange and rates of back-exchange are slowed by subsequently changing the $\mathrm{pH}$ to acidic conditions. Using MS, the content of deuterium in molecules, for instance, peptides after proteolytic cleavage, can be determined and thereby provides information on the degree of exposure.

In a similar fashion, hydroxyl radical footprinting (HRF) involves the reaction of solvent accessible amino acid residues with hydroxyl radicals forming oxidised products (Maleknia et al., 1999; Xu and Chance, 2007). Hydroxyl radicals are usually generated chemically (Fenton chemistry) or photolytically from peroxide or through radiolysis of water. The advantage of HRF is that the modifications are irreversible, and the labelled residues can be identified by database searching in standard experiments. HRF has been optimised to fast photochemical oxidation of proteins (FPOP) utilising photolysis of hydrogen peroxide for the generation of hydroxyl radicals (Hambly and Gross, 2005; Li et al., 2018). In this manner, FPOP enables tuning the footprinting time scale allowing to study proteins in near-native conformations.

Solvent accessible amino acids can also be modified using chemical reagents which specifically react with certain amino acids. There are various chemical reagents which have successfully been used to explore the structures of proteins; examples are diethylpyrocarbonate (Zhou and Vachet, 2012) or 1-ethyl-3-(3-dimethylaminopropyl)carbodiimide hydrochloride (Akashi et al., 1997). When compared with H/D exchange it is a simpler and less expensive approach to gain insights into the topology of membrane protein complexes. In addition, no specialised equipment such as lasers is required. However, chemical labelling is often restricted to certain amino acid residues and therefore strongly depends on the protein of interest. Furthermore, an excess of chemical labels always bears the risk of denaturation whereas H/D exchange is chemically neutral. In addition, H/D exchange is compatible with detergent solubilised membrane proteins. H/D exchange and FPOP both provide labelling time-scales comparable with native conformational dynamics. Nonetheless, all approaches have successfully been applied to study membrane proteins and were recently integrated with other structural techniques to generate computational models (Padayatti et al., 2013; Schmidt et al., 2017a; Martens et al., 2018).

\section{Protein interactions of membrane protein complexes}

Similar to covalent labelling, chemical cross-linking includes the chemical reaction of specific surfaceexposed amino acid residues. Usually, bi-functional cross-linkers composed of two reactive groups and a flexible linker of defined length are used to covalently link amino acids in close proximity, i.e. within the range of the linker (Rappsilber, 2011; Sinz, 2014). A variety of homoand heterobifunctional cross-linkers has been introduced to increase the range of potential targets (Leitner et al., 2016). The most popular cross-linker is the amine-reactive bis-sulfosuccinimidyl-suberate (BS3) (Partis et al., 1983; Iacobucci et al., 2018) which specifically links lysine residues and the protein $\mathrm{N}$-terminus as well as serine, threonine and tyrosine in side reactions (Figure 3A) (Kalkhof and Sinz, 2008; Mädler et al., 2009). Nonetheless, MScleavable cross-linkers which facilitate identification and data analysis of cross-linked peptides gained popularity in recent applications (Sinz, 2017; Yu and Huang, 2017).

The Identification of covalently linked amino acids by MS follows a similar principle as the identification of protein subunits described. The proteins are first hydrolysed into peptides which are then analysed by LC-MS/MS. An example spectrum is shown in Figure 3B. Due to the generally low abundance of the cross-linked di-peptides, an enrichment step using size-exclusion chromatography (Leitner et al., 2010) or strong cation-exchange chromatography (Maiolica et al., 2007) is often included before MS analysis. For data analysis specialised search algorithms are implemented as the computational combination of linear peptides yielding cross-linked di-peptides dramatically increases the search space (Götze et al., 2011; Walzthoeni et al., 2012; Yang et al., 2012; Hoopmann et al., 2015; Liu et al., 2015). However, automated annotation of cross-linking spectra is still a challenge and manual 
A

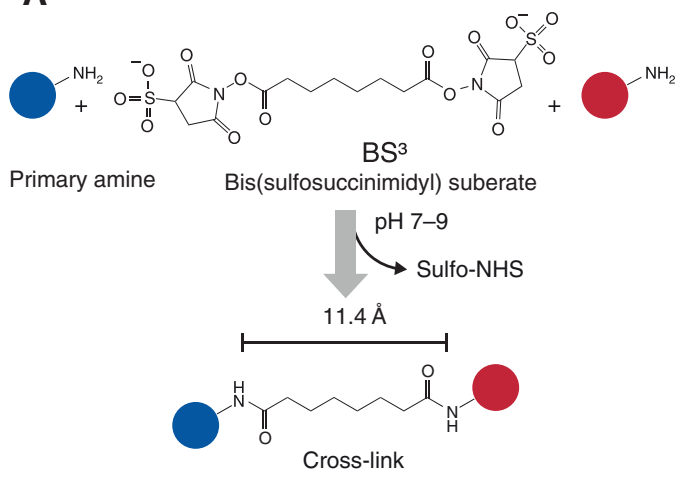

C

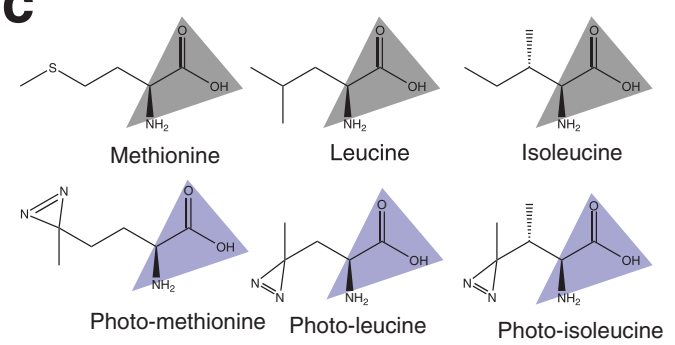

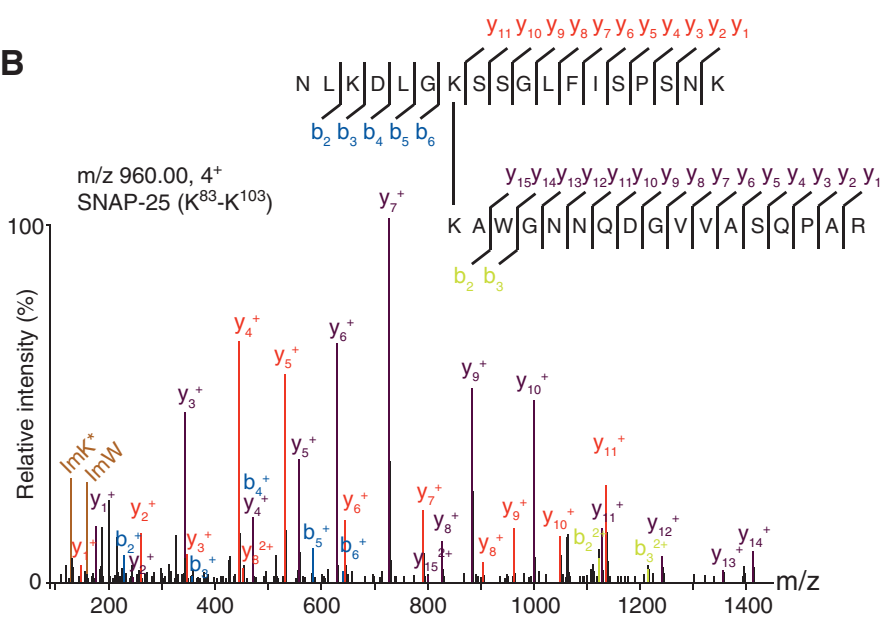

D
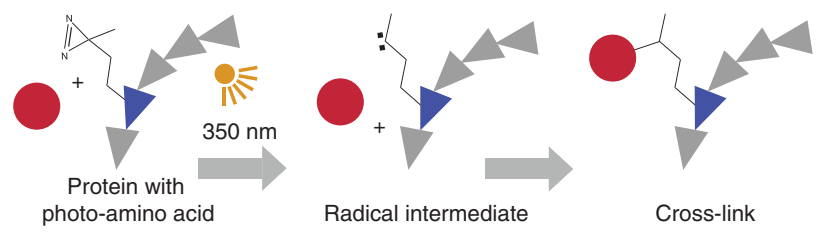

Cross-link

Figure 3: Cross-linking MS using BS3 and photo-amino acids.

(A) Structure and reaction mechanism of BS3. (B) Fragment spectrum of a cross-linked di-peptide of SNAP-25. Characteristic b-and y-ions of both peptides are labelled. (C) Structure of methionine, leucine and isoleucine and their photo-activatable analogues. (D) Schematic of light-induced cross-linking.

evaluation of assigned mass spectra is, therefore, strongly encouraged (Iacobucci and Sinz, 2017).

Cross-linking eventually delivers a list of residue pairs in close proximity within a protein or a protein complex. These distance restraints alone are usually insufficient for de novo modelling of protein complexes, however, when integrated with structural information obtained from other techniques, cross-linking contributes to the generation of computational models (Kalisman et al., 2012; Thalassinos et al., 2013; Erzberger et al., 2014; Politis et al., 2014; Lukoyanova et al., 2015). Particularly the combination of cross-linking with cryo-electron microscopy shows great potential and has recently been applied to solve the structures of several macromolecular machines (Schmidt and Urlaub 2017). A compelling example is the recently established structure of the MHC peptide-loading complex comprising the membraneembedded TAP-transporter, the membrane-anchored MHC and tapasin complexes (Blees et al., 2017).

Importantly, cross-linking is not restricted by the size of the protein complex under investigation and is therefore well-suited to complement structural studies of large multiprotein assemblies (Leitner et al., 2016). Moreover, it is capable of visualising structural dynamics in a quantitative manner (Chen and Rappsilber, 2018). For this, distinct conformational states of a protein or protein complex are cross-linked separately using either differentially labelled cross-linking reagents (Schmidt and Robinson, 2014) or labelled proteins (Arlt et al., 2017). After cross-linking, the differently cross-linked samples are pooled and processed together. Differences in protein interactions are then obtained by comparing the cross-linking intensities.

The cross-linking approaches described have successfully been applied to several membrane-associated protein machines including, for instance, ATP synthases (Schmidt et al., 2013, 2017b) or the ryanodine receptor (Efremov et al., 2015). However, the employed cross-linking reagents targeted mostly the large, soluble domains of these protein complexes. Alternative strategies are therefore needed to gain orthogonal information on the protein interactions formed within the lipid membrane. One promising solution is the introduction of photoreactive leucine, isoleucine or methionine into the protein sequence (Figure 3C) (Suchanek et al., 2005). These amino acids are predominantly represented in the hydrophobic membrane domains of proteins and, upon ultra violet 
(UV)-irradiation, react with any hetero-atom in close proximity (Figure 3D) (Kolbel et al., 2012). They are therefore particularly suited to study the structures of membrane proteins.

\section{Stoichiometries and structural arrangements of membrane protein complexes}

A complementary MS approach is the direct analysis of intact protein complexes in the gas phase of the mass spectrometer (often termed 'native MS') (Leney and Heck, 2017). In contrast to conventional MS, there are two prerequisites for native MS: first, aqueous, volatile buffers at physiological $\mathrm{pH}$ are required to preserve the structure of the protein complexes during ESI (Hernández and Robinson, 2007). For this, the sample is usually transferred to ammonium acetate prior to MS analysis (Hernández and Robinson, 2007). The second requirement is to maintain non-covalent interactions and preferably the structural arrangements of the protein subunits in the gas phase of the mass spectrometer. To achieve this goal, several instrument modifications are required which mostly target the mass range of the quadrupole and the pressure regimes in the different ion stages to facilitate transmission of high mass ions (Sobott et al., 2002).

Knowing the exact masses of the protein subunits, for example, by MS-based identification (see above), the obtained masses of the intact protein complexes from native MS spectra provide information on the complex stoichiometry (Figure 4A) (Taverner et al., 2008). Moreover, similar to the workflows described, native MS provides

A
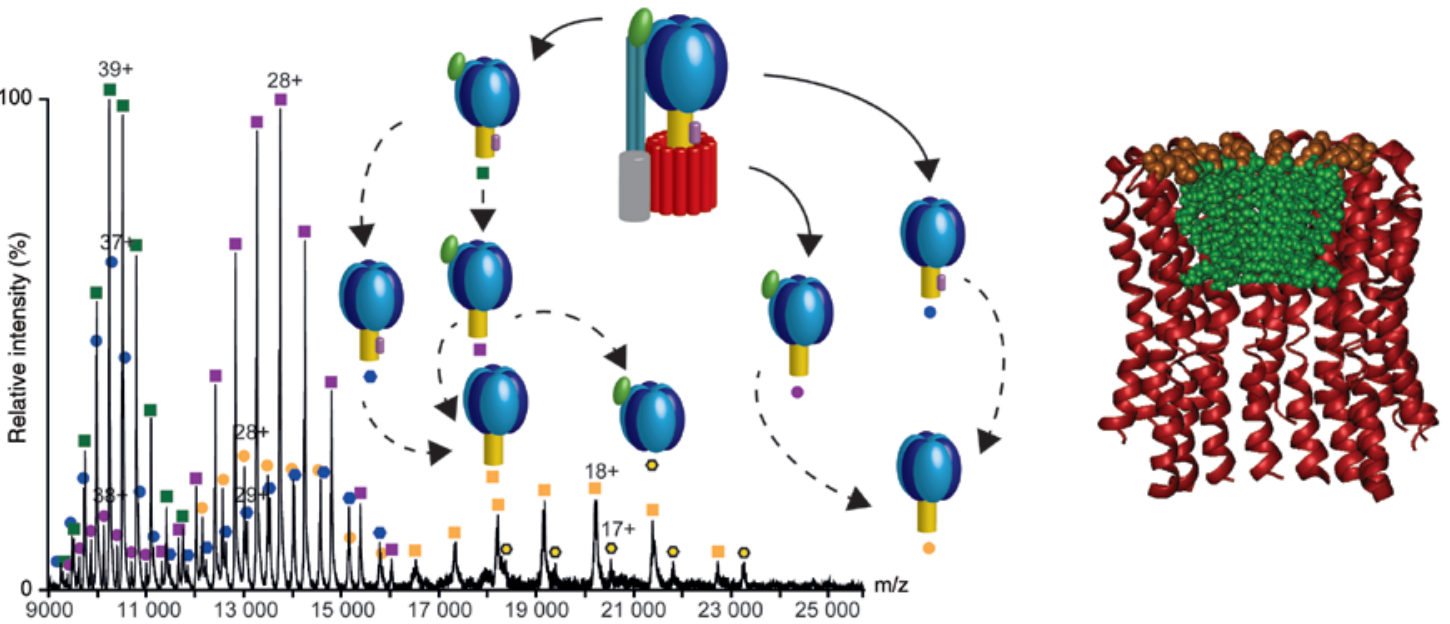

B

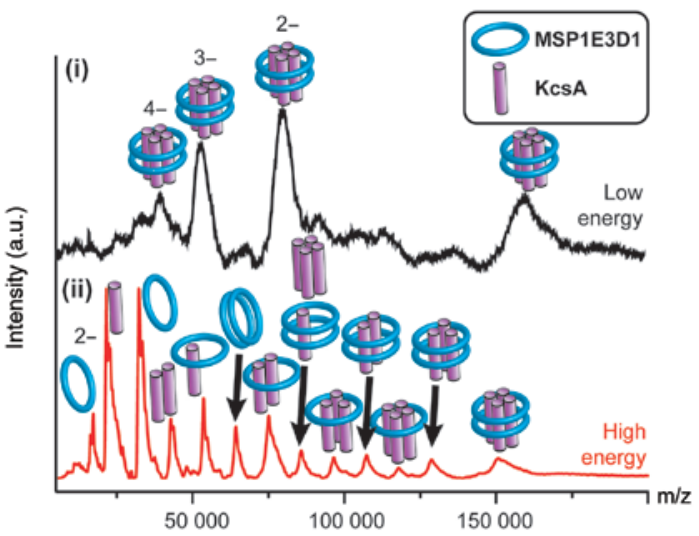

C

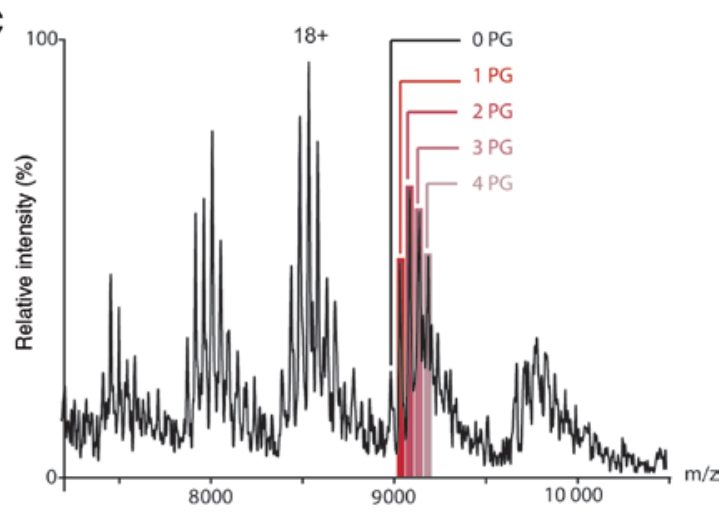

Figure 4: Native MS of membrane protein reveals stoichiometries, protein interactions and lipid binding.

(A) Mass spectrum (lhs) of the chloroplast ATP synthase. Complexes from in solution (solid arrows) and gas phase (dashed arrows) dissociation are observed. A computational model of lipid binding to the membrane ring is shown (rhs). Figure adapted from Schmidt et al. (2013). (B) LILBID MS analysis of KcsA complexes formed in nanodisc. Under mild activation conditions (black) the KcsA tetramer with two scaffold proteins is observed. Dissociation of the complexes occurs at higher energy (red) and reveals single proteins and subcomplexes. Figure adapted from Henrich et al. (2017a). (C) Protein-lipid complexes of the trimeric ammonium channel AmtB. Peaks indicate binding of multiple lipids (highlighted). Figure adapted from Landreh et al. (2016). 
the possibility to select ions for tandem MS experiments. Here, peripheral protein subunits dissociate from the full complex resulting in the unfolded protein subunit as well as so-called 'stripped' complexes (Hernández and Robinson, 2007). The combination of protein stoichiometries observed in solution and the identification of peripheral subunits in tandem MS experiments therefore delivers information on the protein complex topology.

Importantly, native MS is applicable to membrane proteins. However, only a subset of non-ionic detergents is compatible with MS analysis. Therefore, these detergents have to be screened for protein stability during extraction or the proteins have to be transferred into compatible detergents directly prior to MS analysis (Laganowsky et al., 2013). The proteins, together with the detergent micelle, are then transferred to the gas phase where the micelle is removed by collisional activation releasing the free proteins or intact protein complexes. It is generally assumed that activation energy is mostly absorbed during detergent removal; in other words, the micelle protects the protein from collisional induced unfolding (Barrera et al., 2008).

In this way, the stoichiometries and topologies of many membrane protein complexes were established. Examples are ion channels and transporters (Barrera et al., 2009), ATP synthases (Hoffmann et al., 2010; Zhou et al., 2011; Schmidt et al., 2013, 2017b) and additional enzymes of the electron transport chain (Liko et al., 2016; Zhang et al., 2017). In addition to the structural characterisation of membrane proteins, native MS also delivers insights into their mode of action. For instance, native MS could show that the cytotoxic translocon of colicin incorporates two pores of the $\mathrm{OmpF}$ trimer leaving one pore accessible for a target peptide (Housden et al., 2013).

When combined with ion mobility (IM) spectrometry, native MS also delivers information on the shape of an ion, e.g. a protein subunit, a subcomplex or a fully assembled complex (Uetrecht et al., 2010). For this, the ions travel in the IM cell against the counter-flow of a buffer gas (e.g. argon). Larger and more extended ions experience more collisions with the gas molecules and therefore migrate slower, while smaller, compact ions migrate faster. In this way, ions with the same mass-to-charge ratio but different conformations are separated by their collisional cross section (CCS). This approach was successfully used to characterise the effect of detergent removal on the structure of the mechanosensitive channel of large conductance (MscL) (Konijnenberg et al., 2014). Native MS revealed up to six Triton X-100 detergent molecules bound to the MscL complex. Under mild activation conditions, these detergent-bound states showed a compact conformation. However, when the activation energy was increased and the detergent molecules were stripped off the protein, an extended conformation was observed indicating unfolding of the protein in the absence of detergent. Similarly, by increasing the collisional energy in the mass spectrometer and thereby inducing unfolding of the protein (a procedure known as 'collisional induced unfolding') the stability of membrane proteins in the presence of various lipids can be assessed (Laganowsky et al., 2014).

\section{Studying membrane proteins in a native-like environment}

As already discussed, proteins and lipids are not separate entities and should ideally be studied together. There are several possibilities to mimic natural membranes. A very popular solution are nanodiscs which are comprised of two amphipathic proteins forming a belt around a phospholipid bilayer in which the proteins are embedded (Bayburt and Sligar, 2009). In a similar fashion, amphipols (amphipathic polymers) solubilise membrane proteins in a detergent-free aqueous system by wrapping their hydrophobic domains (Tribet et al., 1996). Bicelles represent disc-shaped membrane sections which assemble from long-chain phospholipids constituting the lipid bilayer and short-chain phospholipids or detergents forming the rim (Sanders and Landis, 1995). First attempts employing nanodiscs, bicelles and amphipols for native MS showed that the proteins can be released intact from these membrane mimetics (Hopper et al., 2013). While bicelles and nanodics were able to maintain the multimeric states of membrane proteins, amphipols showed only low amounts of the correct stoichiometries. Both, nanodiscs and bicelles showed to a large extend lipid clusters. These clusters were also explored in their protein-free forms (Marty et al., 2015, 2016a,b). Nanodiscs were then specifically engineered for future native MS applications eliminating interference with lipids (Reid et al., 2017).

A similar approach to ESI is laser-induced liquid bead ion desorption (termed LILBID) (Wattenberg et al., 2000; Morgner et al., 2007). Here, ions are generated from liquid droplets by irradiation with a laser. One of the advantages of LILBID over ESI is its tolerance towards salt and detergents during the ionisation process (Peetz et al., 2018). Moreover, LILBID has proven a suitable method when studying membrane proteins embedded in membrane mimetics such as nanodiscs (Figure 4B) (Henrich et al., 2017a,b) or styrene-maleic acid copolymers (SMALPs) 
(Hellwig et al., 2018). As such, protein insertion from a cell-free expression system into the lipid bilayer of a nanodisc could be followed and uncovered protein oligomerisation dependent on the lipid composition and reaction conditions (Henrich et al., 2017b; Peetz et al., 2017).

The simplest membrane mimetics are probably spherical liposomes which can be prepared from almost any lipid mixture and at various sizes. However, in terms of curvature, spherical membrane mimetics do not always represent the ideal lipid environment; they rather mimic vesicular structures. To-date liposomes were not yet employed to stabilise recombinantly expressed proteins for MS analyses, however, lipid identification and quantification was realised and is promising in future applications (Frick et al., 2018). Notably, recent advancements in sample preparation utilising vesicles prepared from native membranes, successfully allowed the analysis of membrane protein complexes in a detergent- and membrane mimic-free environment promising spectacular future applications (Chorev et al., 2018).

\section{Protein-associated lipids}

Membrane-embedded proteins are surrounded by a shell of directly interacting lipids (often termed the lipid annulus) and, in the periphery, bulk lipids of the respective membranes. The lipid annulus involves specific interactions with lipids at defined sites (structural lipids), interactions with a preferred subset of lipids or non-specific proteinlipid interactions with bulk lipids (Landreh et al., 2016). As prediction of lipid binding sites as well as the specific lipid species based on the protein sequence is impossible, this information has to be obtained experimentally. A native MS spectrum revealing lipid binding to the ammonia transporter AmtB is shown in Figure 4C.

The various detergents used for membrane protein solubilisation differ in their ability to remove or maintain lipids from the membrane environment (Laganowsky et al., 2013). As an example, solubilisation of the heterodimeric ABC transporter TmrAB from Thermus thermophilus using DDM maintained a large fraction of associated lipids which made the analysis by native MS impossible (Bechara et al., 2015). However, after extended delipidation, charge states of the dimeric species were observed. While lipidomics revealed PE and PG bulks lipids, only PG lipids were found to specifically associate with the delipidated protein.

While native MS reveals direct association of lipids and proteins, it does not provide information on their interaction sites. However, in special cases, a combination of native MS, lipidomics and computational modelling unravelled sites of interaction. For 'monomeric' cytochrome c oxidase ( $\mathrm{CcO}$, a protein complex comprising 13 subunits) (Kadenbach et al., 1983) and the dimeric complex thereof (comprising 26 protein subunits) a large number of associated lipids was anticipated by native MS (Liko et al., 2016). The mass difference between the monomeric and dimeric complexes revealed the mass of associated lipids that reside in the central cavity of $\mathrm{CcO}$ as revealed by X-ray crystallography (Shinzawa-Itoh et al., 2007). The number of associated lipids could be calculated from the volume of the cavity as well as the lipid species identified in lipidomics experiments (Liko et al., 2016).

In a similar fashion, the lipid 'plug' of various ATP synthases was identified (Zhou et al., 2011; Schmidt et al., 2013). Following native MS and quantification of identified lipids, computational modelling delivered models of the membrane ring of these ATP synthases interacting with specific lipids (Figure 4A). These interactions involved in all cases charged amino acid residues on top of the membrane ring in close contact with charged lipid molecules.

\section{Protein-lipid interaction sites}

While native MS and lipidomics identify membrane protein associated lipids, their direct interaction sites are crucial for their structure and biological function. In some cases, this can be obtained by comparing the chemical properties of the identified lipids with a crystal structure (Marcoux et al., 2013). Recent examples employed molecular dynamics simulations to predict lipid binding sites in membrane channels and transporters (Laganowsky et al., 2014; Martens et al., 2018; Pyle et al., 2018).

In first experiments, the physical interactions between sphingomyelin and the COP1 machinery protein p24 were probed using radioactive and photosensitive lipid molecules (Contreras et al., 2012). After photo-activation, these molecules covalently attach to amino acid residues in close proximity. The labelled protein can then be detected by autoradiography. However, mutation analyses are required to map the lipid binding site following this approach. Other studies showed the potential of UV-activatable lipids to probe their interactions (Lindner et al., 2017). However, these studies can only be performed after recombinant expression or detergent-based purification of membrane proteins and are not accessible for proteins in their natural lipid environment. 
A more elegant solution is the potential application of chemical cross-linking reagents to probe protein-lipid interactions (Scacioc et al., 2017). Employing BS3 crosslinker (see above) revealed oligomerisation of autophagyrelated protein Atg18 in the presence of a lipid bilayer and, importantly, also unravelled first lipid adducts after reaction with BS3 (Scacioc et al., 2017).

\section{Supporting functional conclusions}

MS experiments unravel many aspects of membrane protein-lipid interactions; however, they lack the high spatial resolution of classical structural techniques. Nonetheless, the integration of low-resolution restraints from MS with computational simulation is often fruitful and helps addressing many biological questions (Politis and
Borysik, 2015; Politis and Schmidt 2018; Marklund and Benesch, 2019).

Of the MS deliverables, CCSs are useful measures to compare experimental observations with theoretical calculations. As an example, the lipid binding sites of AmtB, Aquaporin $\mathrm{Z}$ and MscL were successfully mapped onto their high-resolution structures by comparing models of the proteins in a lipid bilayer obtained from molecular dynamics (MD) simulations with experimentally determined CCSs (Laganowsky et al., 2014). In a similar fashion, MD simulations of MscL in a lipid bilayer of defined membrane tension allowed rationalising experimental cross sections. For this, theoretical CCSs of the observed conformational states were calculated and compared with the experimental values revealing different functional states of the transporter (Konijnenberg et al., 2014). MD simulations of a protein-detergent complex in a gas-phase

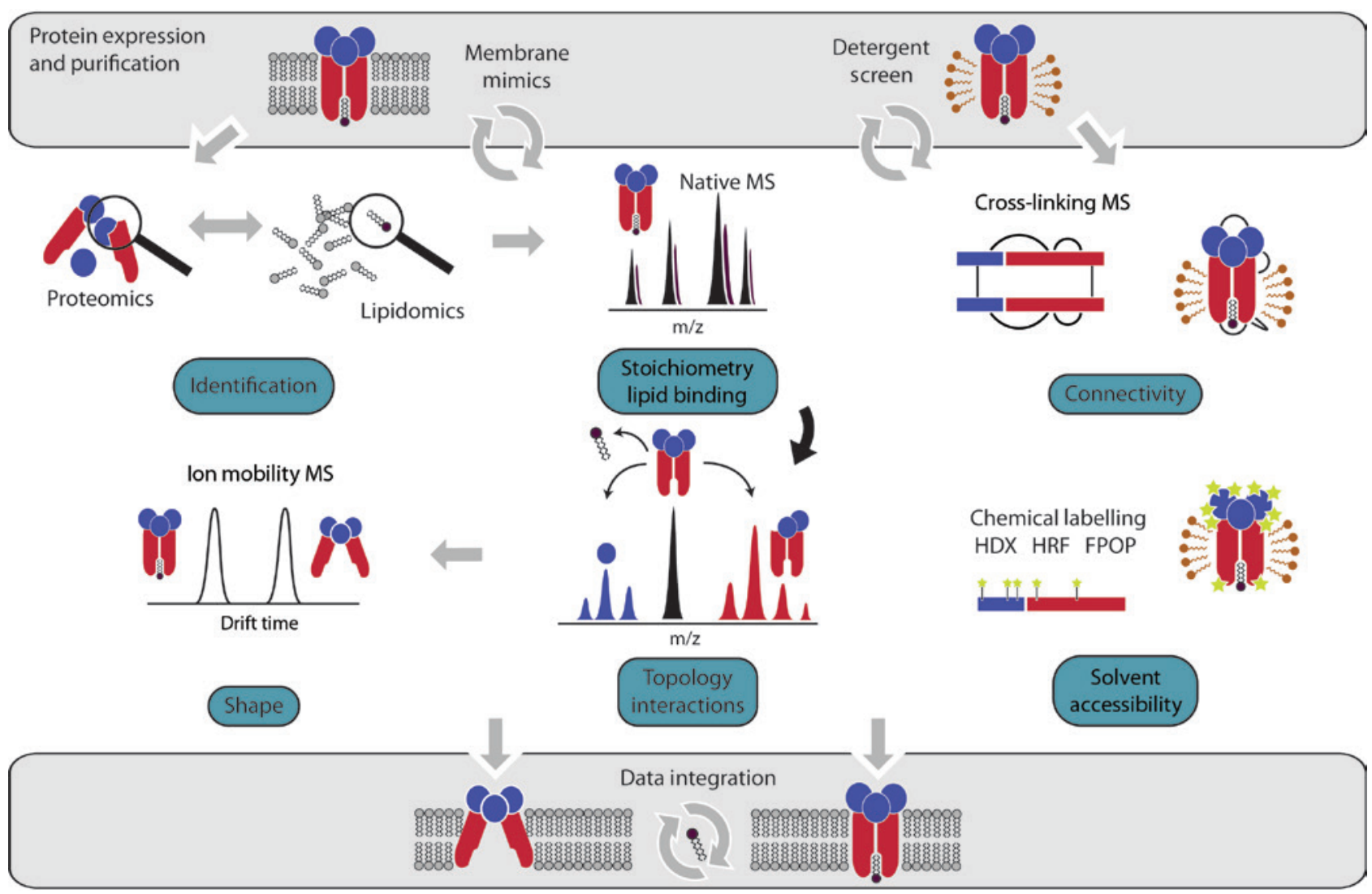

Figure 5: Overview on MS techniques for membrane protein analysis.

MS guides expression and purification of membrane protein complexes as well as their incorporation into membrane mimetics. Proteomics and lipidomics identify the components of membrane protein complexes. Stoichiometries of proteins and lipids as well as interactions and topologies are revealed by native MS. The combination with ion mobility further delivers information on the shape of the ions. Crosslinking MS reveals protein interaction sites while chemical labelling approaches as well as H/D exchange, FPOP and HRF unravel the surface accessible area. Data obtained from these techniques can be integrated into modelling approaches for generation of models. For a detailed description of each approach refer to the main text. 
mimicking environment further showed migration of the detergent molecules to the periphery of the protein yielding an increase in CCS which was also observed experimentally (Borysik, 2015).

In addition to CCSs, computational approaches help interpreting collision induced unfolding events. For example, MD simulations of lipid-free NapA captured an experimentally observed unfolding event. Simulation of $\mathrm{PE}$ binding to the same protein revealed stabilisation of the protein by attachment of the lipid head group even at increased temperatures. This was evidenced by the PE-induced stabilisation of NapA during collision induced unfolding (Landreh et al., 2017).

Another impressive example is a recent study on the conformational dynamics of the homologous transporters XylE, LacY and GlpT using H/D exchange MS. After identifying a charge-relay network in the homologous transporters, the authors performed MD simulations showing that PE but not PC directly interacts with the residues of the network (Martens et al., 2018).

\section{Outlook and conclusions}

As demonstrated in the preceding paragraphs, many aspects of protein-lipid interactions within biological membranes are accessible through MS (see Figure 5 and Table 1 for a summary). While protein and lipid identification are key for defining the environment in which a protein resides, structural MS techniques provide a more holistic view onto protein-protein and protein-lipid interactions. The low sample consumption and short analysis time as well as the possibility to analyse heterogeneous mixtures make it a prime technology when other

Table 1: Techniques of structural MS for studying membrane protein complexes.

\begin{tabular}{|c|c|c|}
\hline Method & Working principle & Outcome \\
\hline $\begin{array}{l}\text { MS-based } \\
\text { lipidomics }\end{array}$ & $\begin{array}{ll}\text { - } & \text { MS/MS analysis of lipids in organic solvents } \\
\text { - } & \text { Identification of lipid classes and fatty acyl chains by char- } \\
& \text { acteristic fragment ions and neutral losses } \\
\text { - } & \text { Quantification by comparison of MS peak areas }\end{array}$ & $\begin{array}{l}\text { - Identification of lipid classes and species } \\
\text { - Relative or absolute quantification of } \\
\text { lipids }\end{array}$ \\
\hline $\begin{array}{l}\text { Proteomics/ } \\
\text { identification }\end{array}$ & $\begin{array}{l}\text { - } \text { Site-specific proteolysis of proteins } \\
\text { - LC-MS/MS analysis of peptides } \\
\text { - Comparison of precursor and fragment masses with data- } \\
\text { base of in silico generated peptides and their fragments }\end{array}$ & $\begin{array}{l}\text { - } \text { Identification of proteins } \\
\text { - } \text { Mapping of post-translational modifica- } \\
\text { tions } \\
\text { - }\end{array}$ \\
\hline Cross-linking MS & $\begin{array}{l}\text { - Cross-linking of proximate residues } \\
\text { - } \text { Site-specific proteolysis of proteins } \\
\text { - } \text { LC-MS/MS of di-peptides } \\
\text { - Comparison of precursor and fragment masses with data- } \\
\text { base. } \text { Requires specialised software }\end{array}$ & $\begin{array}{l}\text { - List of residue pairs in close proximity } \\
\text { - Information on solvent accessibility }\end{array}$ \\
\hline $\mathrm{H} / \mathrm{D}$ exchange MS & $\begin{array}{l}\text { - } \text { Solvent accessible protons are exchanged against deuterium } \\
\text { - Non-specific on-line proteolysis } \\
\text { - LC-MS/MS } \\
\text { - Comparison of precursor and fragment masses with data- } \\
\text { base of in silico generated peptides and their fragments }\end{array}$ & $\begin{array}{l}\text { - Intensity of deuterated vs. unmodified } \\
\text { peptides } \\
\text { - } \text { (Aqueous) solvent accessibility }\end{array}$ \\
\hline Covalent labelling & $\begin{array}{l}\text { - Covalent attachment of label to specific residues } \\
\text { - } \text { Site-specific proteolysis of proteins } \\
\text { - } \text { LC-MS/MS analysis of peptides } \\
\text { - Comparison of precursor and fragment masses with data- } \\
\text { base of in silico generated peptides and their fragments }\end{array}$ & $\begin{array}{l}\text { - } \text { Identification of modified peptides } \\
\text { - } \text { Intensity of modified vs. unmodified } \\
\text { peptides } \\
\text { - }\end{array}$ \\
\hline Native MS & $\begin{array}{l}\text { - Direct injection of intact protein complexes into a high mass } \\
\text { modified instrument } \\
\text { - } \text { Collision induced removal of detergent micelles or } \\
\text { membrane mimetics (e.g. nanodiscs, bicelles) } \\
\text { - } \text { MS and MS/MS analysis } \\
\text { - } \quad \text { (Manual) annotation of spectra }\end{array}$ & $\begin{array}{l}\text { - Complex stoichiometry } \\
\text { - Topology } \\
\text { - Lipid binding }\end{array}$ \\
\hline IM MS & $\begin{array}{l}\text { - Drift of charged ions against an inert counter-flow gas } \\
\text { - Retention of ions with a larger CCS }\end{array}$ & $\begin{array}{l}\text { - Relative shape of the ions } \\
\text { - Discriminate conformers of the same mass }\end{array}$ \\
\hline
\end{tabular}

The working principle and outcome are given for each of the discussed methods. 
strategies prove difficult. However, it becomes apparent that membrane proteins and lipids are not separate entities but strongly interdependent. To gain profound insights into their function, the combination of biochemical and biophysical techniques is needed. Here, MS serves as an orthogonal approach which complements other structural techniques such as cryo-electron microscopy or NMR spectroscopy or provides clues to be followed up by biochemical strategies.

The reconstitution of proteins into membrane vesicles of native-like composition, for instance planar nanodiscs or spherical liposomes, as well as their extraction from native membranes together with their surrounding lipids, for instance in so-called SMALPs, are a promising venture for future studies of membrane proteins in an active lipid environment. Together with advancements in computational simulation and modelling, MS can in future applications serve as a toolbox for the structural analysis of membrane proteins and their complexes (Figure 5, Table 1).

Acknowledgements: We thank Michael Landreh (Karolinksa Institutet), Carol Robinson (University of Oxford), Nina Morgner, Oliver Peetz (Goethe-Universität Frankfurt am Main), Sabine Wittig, Tommy Hofmann and Julia Hesselbarth (Martin Luther University HalleWittenberg) for providing mass spectra, and Sabine Wittig and Melissa Frick for comments on our manuscript. We acknowledge funding from the Federal Ministry for Education and Research (BMBF, ZIK programme, Funder Id: http://dx.doi.org/10.13039/501100002347, 03Z22HN22), the European Regional Development Funds (EFRE, ZS/2016/04/78115) and the Martin Luther University Halle-Wittenberg.

\section{References}

Akashi, S., Shirouzu, M., Terada, T., Ito, Y., Yokoyama, S., and Takio, K. (1997). Characterization of the structural difference between active and inactive forms of the Ras protein by chemical modification followed by mass spectrometric peptide mapping. Anal. Biochem. 248, 15-25.

Ambrose, S., Housden, N.G., Gupta, K., Fan, J., White, P., Yen, H., Marcoux, J., Kleanthous, C., Hopper, J.T.S., and Robinson, C.V. (2017). Native desorption electrospray ionization liberates soluble and membrane protein complexes from surfaces. Angew. Chem. Int. Ed. 129, 14655-14660.

Arlt, C., Flegler, V., Ihling, C.H., Schafer, M., Thondorf, I., and Sinz, A. (2017). An integrated mass spectrometry based approach to probe the structure of the full-length wild-type tetrameric p53 tumor suppressor. Angew. Chem. Int. Ed. 56, 275-279.
Barrera, N.P., Di Bartolo, N., Booth, P.J., and Robinson, C.V. (2008). Micelles protect membrane complexes from solution to vacuum. Science 321, 243-246.

Barrera, N.P., Isaacson, S.C., Zhou, M., Bavro, V.N., Welch, A., Schaedler, T.A., Seeger, M.A., Miguel, R.N., Korkhov, V.M., van Veen, H.W., et al. (2009). Mass spectrometry of membrane transporters reveals subunit stoichiometry and interactions. Nat. Methods 6, 585-587.

Bayburt, T.H. and Sligar, S.G. (2009). Membrane protein assembly into nanodiscs. FEBS Lett. 584, 1721-1727.

Bechara, C., Nöll, A., Morgner, N., Degiacomi, M.T., Tampé, R., and Robinson, C.V. (2015). A subset of annular lipids is linked to the flippase activity of an ABC transporter. Nat. Chem. 7, 255-262.

Bigay, J. and Antonny, B. (2012). Curvature, lipid packing, and electrostatics of membrane organelles: defining cellular territories in determining specificity. Dev. Cell 23, 886-895.

Blees, A., Januliene, D., Hofmann, T., Koller, N., Schmidt, C., Trowitzsch, S., Moeller, A., and Tampé, R. (2017). Structure of the human MHC-I peptide-loading complex. Nature 551, 525-528.

Bligh, E.G. and Dyer, W.J. (1959). A rapid method for total lipid extraction and purification. Can. J. Biochem. Physiol. 37, 911-917.

Borysik, A.J. (2015). Structure and dynamics of a protein-surfactant assembly studied by ion-mobility mass spectrometry and molecular dynamics simulations. Anal. Chem. 87, 8970-8976.

Brugger, B., Erben, G., Sandhoff, R., Wieland, F.T., and Lehmann, W.D. (1997). Quantitative analysis of biological membrane lipids at the low picomole level by nano-electrospray ionization tandem mass spectrometry. Proc. Natl. Acad. Sci. USA 94, 2339-2344.

Chen, Z.A. and Rappsilber, J. (2018). Protein dynamics in solution by quantitative crosslinking/mass spectrometry. Trends Biochem. Sci. 43, 908-920.

Chorev, D.S., Baker, L.A., Wu, D., Beilsten-Edmands, V., Rouse, S.L., Zeev-Ben-Mordehai, T., Jiko, C., Samsudin, F., Gerle, C., Khalid, S., et al. (2018). Protein assemblies ejected directly from native membranes yield complexes for mass spectrometry. Science 362, 829-834.

Contreras, F.-X., Ernst, A.M., Haberkant, P., Björkholm, P., Lindahl, E., Gönen, B., Tischer, C., Elofsson, A., Heijne, G.v., Thiele, C., et al. (2012). Molecular recognition of a single sphingolipid species by a protein's transmembrane domain. Nature 481, 525-529.

Cooke, I.R. and Deserno, M. (2006). Coupling between lipid shape and membrane curvature. Biophys. J. 91, 487-495.

Efremov, R.G., Leitner, A., Aebersold, R., and Raunser, S. (2015). Architecture and conformational switch mechanism of the ryanodine receptor. Nature 517, 39-43.

Erzberger, J.P., Stengel, F., Pellarin, R., Zhang, S., Schaefer, T., Aylett, C.H.S., Cimermancic, P., Boehringer, D., Sali, A., Aebersold, R., et al. (2014). Molecular architecture of the 40SeIF1elF3 translation initiation complex. Cell 158, 1123-1135.

Fagerberg, L., Jonasson, K., Heijne, G.v., Uhlén, M., and Berglund, L. (2010). Prediction of the human membrane proteome. Proteomics 10, 1141-1149.

Folch, J., Lees, M., and Slaone Stanley, G.H. (1957). A simple method for the isolation and purification of total lipids from animal tissues. J. Biol. Chem. 226, 497-509.

Frick, M., Hofmann, T., Haupt, C., and Schmidt, C. (2018). A novel sample preparation strategy for shotgun lipidomics of phospholipids employing multilamellar vesicles. Anal. Bioanal. Chem. 410, 4253-4258. 
Fuchs, B., Süss, R., Teuber, K., Eibisch, M., and Schiller, J. (2011). Lipid analysis by thin-layer chromatograph - a review of the current state. J. Chromatogr. A 1218, 2754-2774.

Götze, M., Pettelkau, J., Schaks, S., Bosse, K., Ihling, C.H., Krauth, F., Fritzsche, R., Kühn, U., and Sinz, A. (2011). StavroX - a software for analyzing crosslinked products in protein interaction studies. J. Am. Soc. Mass Spectrom. 23, 76-87.

Griss, J., Martín, M., O’Donovan, C., Apweiler, R., Hermjakob, H., and Vizcaíno, J.A. (2011). Consequences of the discontinuation of the International Protein Index (IPI) database and its substitution by the UniProtKB “complete proteome" sets. Proteomics $11,4434-4438$.

Hambly, D.M. and Gross, M.L. (2005). Laser flash photolysis of hydrogen peroxide to oxidize protein solvent-accessible residues on the microsecond timescale. J. Am. Soc. Mass Spectrom. 16, 2057-2063.

Han, X. and Gross, R.W. (2005). Shotgun lipidomics: Electrospray ionization mass spectrometric analysis and quantitation of cellular lipidomes directly from crude extracts of biological samples. Mass Spectrom. Rev. 24, 367-412.

Harkewicz, R. and Dennis, E.A. (2011). Applications of Mass Spectrometry to Lipids and Membranes. Annu. Rev. Biochem. $80,301-325$.

Hellwig, N., Peetz, O., Ahdash, Z., Tascon, I., Booth, P.J., Mikusevic, V., Diskowski, M., Politis, A., Hellmich, Y., Hanelt, I., et al. (2018). Native mass spectrometry goes more native: investigation of membrane protein complexes directly from SMALPs. Chem. Commun. (Cambr.) 54, 13702-13705.

Henrich, E., Peetz, O., Hein, C., Laguerre, A., Hoffmann, B., Hoffmann, J., Dötsch, V., Bernhard, F., and Morgner, N. (2017a). Analyzing native membrane protein assembly in nanodiscs by combined non-covalent mass spectrometry and synthetic biology. eLife 6, e20954.

Henrich, E., Sormann, J., Eberhardt, P., Peetz, O., Mezhyrova, J., Morgner, N., Fendler, K., Dotsch, V., Wachtveitl, J., Bernhard, F., et al. (2017b). From gene to function: cell-free electrophysiological and optical analysis of ion pumps in nanodiscs. Biophys. J. 113, 1331-1341.

Hernández, H. and Robinson, C.V. (2007). Determining the stoichiometry and interactions of macromolecular assemblies from mass spectrometry. Nat. Protoc. 2, 715-726.

Hoffmann, J., Sokolova, L., Preiss, L., Hicks, D.B., Krulwich, T.A., Morgner, N., Wittig, I., Schägger, H., Meier, T., and Brutschy, B. (2010). ATP synthases: cellular nanomotors characterized by LILBID mass spectrometry. Phys. Chem. Chem. Phys. 12, 13375-13382.

Hoopmann, M.R., Zelter, A., Johnson, R.S., Riffle, M., MacCoss, M.J., Davis, T.N., and Moritz, R.L. (2015). Kojak: efficient analysis of chemically cross-linked protein complexes. J. Proteome. Res. 14, 2190-2198.

Hopper, J.T.S., Yu, Y.T.-C., Li, D., Raymond, A., Bostock, M., Liko, I., Mikhailov, V., Laganowsky, A., Benesch, J.L.P., Caffrey, M., et al. (2013). Detergent-free mass spectrometry of membrane protein complexes. Nat. Methods 10, 1206-1208.

Housden, N.G., Hopper, J.T.S., Lukoyanova, N., Rodriguez-Larrea, D., Wojdyla, J.A., Klein, A., Kaminska, R., Bayley, H., Saibil, H.R., Robinson, C.V., et al. (2013). Intrinsically disordered protein threads through the bacterial outer-membrane porin OmpF. Science 340, 1570-1574.
Hsu, F.F. and Turk, J. (2009). Electrospray ionization with low-energy collisionally activated dissociation tandem mass spectrometry of glycerophospholipids: mechanisms of fragmentation and structural characterization. J. Chromatogr. B Anal. Technol. Biomed. Life Sci. 877, 2673-2695.

lacobucci, C. and Sinz, A. (2017). To be or not to be? Five guidelines to avoid misassignments in cross-linking/mass spectrometry. Anal. Chem. 89, 7832-7835.

lacobucci, C., Piotrowski, C., Aebersold, R., Amaral, B.C., Andrews, P., Borchers, C., Brodie, N.I., Bruce, J.E., Chaignepain, S., Chavez, J.D., et al. (2018). Cross-linking/mass spectrometry: a communitywide, comparative study towards establishing best practice guidelines. bioRxiv, 424697.

Inloes, J.M., Jing, H., and Cravatt, B.F. (2018). The spastic paraplegia-associated phospholipase DDHD1 is a primary brain phosphatidylinositol lipase. Biochemistry 57, 5759-5767.

Junge, F., Schneider, B., Reckel, S., Schwarz, D., Dötsch, V., and Bernhard, F. (2008). Large-scale production of functional membrane proteins. Cell Mol. Life Sci. 65, 1729-1755.

Kadenbach, B., Ungibauer, M., Jarausch, J., Büge, U., and KuhnNentwig, L. (1983). The complexity of respiratory complexes. Trends Biochem. Sci. 8, 398-400.

Kalisman, N., Adams, C.M., and Levitt, M. (2012). Subunit order of eukaryotic TRiC/CCT chaperonin by cross-linking, mass spectrometry, and combinatorial homology modeling. Proc. Natl. Acad. Sci. USA 109, 2884-2889.

Kalkhof, S. and Sinz, A. (2008). Chances and pitfalls of chemical cross-linking with amine-reactive $\mathrm{N}$-hydroxysuccinimide esters. Anal. Bioanal. Chem. 392, 305-312.

Katta, V. and Chait, B.T. (1993). Hydrogen/deuterium exchange electrospray ionization mass spectrometry: a method for probing protein conformational changes in solution. J. Am. Chem. Soc. 115, 6317-6321.

Klose, C., Surma, M.A., and Simons, K. (2013). Organellar lipidomics - background and perspectives. Curr. Opin. Cell Biol. 25, 406-413.

Knowles, T.J., Scott-Tucker, A., Overduin, M., and Henderson, I.R. (2009). Membrane protein architects: the role of the BAM complex in outer membrane protein assembly. Nat. Rev. Microbiol. 7, 206-214.

Kolbel, K., Ihling, C.H., and Sinz, A. (2012). Analysis of peptide secondary structures by photoactivatable amino acid analogues. Angew. Chem. Int. Ed. 51, 12602-12605.

Konijnenberg, A., Yilmaz, D., Ingólfsson, H.I., Dimitrova, A., Marrink, S.J., Li, Z., Vénien-Bryan, C., Sobott, F., and Koçer, A. (2014). Global structural changes of an ion channel during its gating are followed by ion mobility mass spectrometry. Proc. Natl. Acad. Sci. USA 111, 17170-17175.

Laganowsky, A., Reading, E., Allison, T.M., Ulmschneider, M.B., Degiacomi, M.T., Baldwin, A.J., and Robinson, C.V. (2014). Membrane proteins bind lipids selectively to modulate their structure and function. Nature 510, 172-175.

Laganowsky, A., Reading, E., Hopper, J.T.S., and Robinson, C.V. (2013). Mass spectrometry of intact membrane protein complexes. Nat. Protoc. 8, 639-651.

Landreh, M., Marty, M.T., Gault, J., and Robinson, C.V. (2016). A sliding selectivity scale for lipid binding to membrane proteins. Curr. Opin. Struct. Biol. 39, 54-60.

Landreh, M., Marklund, E.G., Uzdavinys, P., Degiacomi, M.T., Coincon, M., Gault, J., Gupta, K., Liko, I., Benesch, J.L.P., 
Drew, D., et al. (2017). Integrating mass spectrometry with MD simulations reveals the role of lipids in $\mathrm{Na}^{+} / \mathrm{H}^{+}$antiporters. Nat. Commun. 8, 13993.

Leitner, A., Faini, M., Stengel, F., and Aebersold, R. (2016). Crosslinking and mass spectrometry: an integrated technology to understand the structure and function of molecular machines. Trends Biochem. Sci. 41, 20-32.

Leitner, A., Walzthoeni, T., Kahraman, A., Herzog, F., Rinner, O., Beck, M., and Aebersold, R. (2010). Probing native protein structures by chemical cross-linking, mass spectrometry, and bioinformatics. Mol. Cell Proteomics 9, 1634-1649.

Leney, A.C. and Heck, A.J.R. (2017). Native mass spectrometry: what is in the name? J. Am. Soc. Mass Spectrom. 28, 5-13.

Li, K.S., Shi, L., and Gross, M.L. (2018). Mass spectrometry-based fast photochemical oxidation of proteins (FPOP) for higher order structure characterization. Acc. Chem. Res. 51, 736-744.

Liko, I., Degiacomi, M.T., Mohammed, S., Yoshikawa, S., Schmidt, C., and Robinson, C.V. (2016). Dimer interface of bovine cytochrome $c$ oxidase is influenced by local posttranslational modifications and lipid binding. Proc. Natl. Acad. Sci. USA 113, 8230-8235.

Lindner, S., Gruhle, K., Schmidt, R., Garamus, V.M., Ramsbeck, D., Hause, G., Meister, A., Sinz, A., and Drescher, S. (2017). Azidemodified membrane lipids: synthesis, properties, and reactivity. Langmuir 33, 4960-4973.

Liu, F., Rijkers, D.T., Post, H., and Heck, A.J. (2015). Proteome-wide profiling of protein assemblies by cross-linking mass spectrometry. Nat. Methods. 12, 1179-1184.

London, E. (2002). Insights into lipid raft structure and formation from experiments in model membranes. Curr. Opin. Struct. Biol. 12, 480-486.

Lukoyanova, N., Kondos, S.C., Farabella, I., Law, R.H.P., Reboul, C.F., Caradoc-Davies, T.T., Spicer, B.A., Kleifeld, O., Traore, D.A.K., Ekkel, S.M., et al. (2015). Conformational changes during pore formation by the perforin-related protein pleurotolysin. PLoS Biol. 13, e1002049.

Ma, X. and Xia, Y. (2014). Pinpointing double bonds in lipids by Paterno-Buchi reactions and mass spectrometry. Angew. Chem. Int. Ed. 53, 2592-2596.

Mädler, S., Bich, C., Touboul, D., and Zenobi, R. (2009). Chemical cross-linking with NHS esters: a systematic study on amino acid reactivities. J. Mass Spectrom. 44, 694-706.

Maiolica, A., Cittaro, D., Borsotti, D., Sennels, L., Ciferri, C., Tarricone, C., Musacchio, A., and Rappsilber, J. (2007). Structural analysis of multiprotein complexes by cross-linking, mass spectrometry, and database searching. Mol. Cell Proteomics. 6, 2200-2211.

Maleknia, S.D., Brenowitz, M., and Chance, M.R. (1999). Millisecond radiolytic modification of peptides by synchrotron X-rays identified by mass spectrometry. Anal. Chem. 71, 3965-3973.

Marcoux, J., Wang, S.C., Politis, A., Reading, E., Ma, J., Biggin, P.C., Zhou, M., Tao, H., Zhang, Q., Chang, G., et al. (2013). Mass spectrometry reveals synergistic effects of nucleotides, lipids, and drugs binding to a multidrug resistance efflux pump. Proc. Natl. Acad. Sci. USA 110, 9704-9709.

Marklund, E.G. and Benesch, J.L. (2019). Weighing-up protein dynamics: the combination of native mass spectrometry and molecular dynamics simulations. Curr. Opin. Struct. Biol. 54, 50-58.

Martens, C., Shekhar, M., Borysik, A.J., Lau, A.M., Reading, E., Tajkhorshid, E., Booth, P.J., and Politis, A. (2018). Direct protein-lipid interactions shape the conformational landscape of secondary transporters. Nat. Commun. 9, 4151.

Marty, M.T., Baldwin, A.J., Marklund, E.G., Hochberg, G.K.A.,

Benesch, J.L.P., and Robinson, C.V. (2015). Bayesian deconvolution of mass and ion mobility spectra: from binary interactions to polydisperse ensembles. Anal. Chem. 87, 4370-4376.

Marty, M.T., Hoi, K.K., Gault, J., and Robinson, C.V. (2016a). Probing the lipid annular belt by gas-phase dissociation of membrane proteins in nanodiscs. Angew. Chem. Int. Ed. 55, 550-554.

Marty, M.T., Hoi, K.K., and Robinson, C.V. (2016b). Interfacing membrane mimetics with mass spectrometry. Acc. Chem. Res. 49, 2459-2467.

Matyash, V., Liebisch, G., Kurzchalia, T.V., Shevchenko, A., and Schwudke, D. (2008). Lipid extraction by methyl-tert-butyl ether for high-throughput lipidomics. J. Lipid Res. 49, 1137-1146.

Mazhab-Jafari, M.T., Rohou, A., Schmidt, C., Bueler, S.A., Benlekbir, S., Robinson, C.V., and Rubinstein, J.L. (2016). Atomic model for the membrane-embedded VO motor of a eukaryotic V-ATPase. Nature 539, 118-122.

McMahon, H.T. and Boucrot, E. (2015). Membrane curvature at a glance. J. Cell Sci. 128, 1065-1070.

Meer, G.v., Voelker, D.R., and Feigenson, G.W. (2008). Membrane lipids: where they are and how they behave. Nat. Rev. Mol. Cell Biol. 9, 112-124.

Milovanovic, D., Honigmann, A., Koike, S., Gottfert, F., Pahler, G., Junius, M., Mullar, S., Diederichsen, U., Janshoff, A., Grubmuller, H., et al. (2015). Hydrophobic mismatch sorts SNARE proteins into distinct membrane domains. Nat. Commun. 6, 5984.

Morgner, N., Kleinschroth, T., Barth, H.D., Ludwig, B., and Brutschy, B. (2007). A novel approach to analyze membrane proteins by laser mass spectrometry: from protein subunits to the integral complex. J. Am. Soc. Mass Spectrom. 18, 1429-1438.

Murray, D.H. and Tamm, L.K. (2011). Molecular mechanism of cholesterol- and polyphosphoinositide-mediated syntaxin clustering. Biochemistry 50, 9014-9022.

Nirenberg, M.W. and Matthaei, J.H. (1961). The dependence of cell-free protein synthesis in E. coli upon naturally occurring or synthetic polyribonucleotides. Proc. Natl. Acad. Sci. USA 47, 1588-1602.

Opekarová, M. and Tanner, W. (2003). Specific lipid requirements of membrane proteins - a putative bottleneck in heterologous expression. Biochim. Biophys. Acta 1610, 11-22.

Overington, J.P., Al-Lazikani, B., and Hopkins, A.L. (2006). How many drug targets are there? Nat. Rev. Drug Discov. 5, 993-996.

Padayatti, P.S., Wang, L., Gupta, S., Orban, T., Sun, W., Salom, D., Jordan, S.R., Palczewski, K., and Chance, M.R. (2013). A hybrid structural approach to analyze ligand binding by the serotonin type 4 receptor (5-HT4). Mol. Cell Proteomics 12, 1259-1271.

Papanikou, E., Karamanou, S., and Economou, A. (2007). Bacterial protein secretion through the translocase nanomachine. Nat. Rev. Microbiol. 5, 839-851.

Partis, M.D., Griffiths, D.G., Roberts, G.C., and Beechey, R.B. (1983). Cross-linking of protein by $\omega$-maleimido alkanoylN-hydroxysuccinimido esters. J. Protein Chem. 2, 263-277.

Peetz, O., Henrich, E., Laguerre, A., Lohr, F., Hein, C., Dotsch, V., Bernhard, F., and Morgner, N. (2017). Insights into cotranslational membrane protein insertion by combined LILBIDmass spectrometry and NMR spectroscopy. Anal. Chem. 89, 12314-12318. 
Peetz, O., Hellwig, N., Henrich, E., Mezhyrova, J., Dotsch, V., Bernhard, F., and Morgner, N. (2018). LILBID and nESI: different native mass spectrometry techniques as tools in structural biology. J. Am. Soc. Mass Spectrom. 30, 181-191.

Politis, A. and Borysik, A.J. (2015). Assembling the pieces of macromolecular complexes: hybrid structural biology approaches. Proteomics 15, 2792-2803.

Politis, A. and Schmidt, C. (2018). Structural characterisation of medically relevant protein assemblies by integrating mass spectrometry with computational modelling. J. Proteomics 175 , 34-41.

Politis, A., Stengel, F., Hall, Z., Hernandez, H., Leitner, A., Walzthoeni, T., Robinson, C.V., and Aebersold, R. (2014). A mass spectrometrybased hybrid method for structural modeling of protein complexes. Nat. Methods 11, 403-406.

Pyle, E., Kalli, A.C., Amillis, S., Hall, Z., Lau, A.M., Hanyaloglu, A.C., Diallinas, G., Byrne, B., and Politis, A. (2018). Structural lipids enable the formation of functional oligomers of the eukaryotic purine symporter UapA. Cell Chem. Biol. 25, 840-848.e844.

Rappsilber, J. (2011). The beginning of a beautiful friendship: crosslinking/mass spectrometry and modelling of proteins and multi-protein complexes. J. Struct. Biol. 173, 530-540.

Reid, D.J., Keener, J.E., Wheeler, A.P., Zambrano, D.E., Diesing, J.M., Reinhardt-Szyba, M., Makarov, A., and Marty, M.T. (2017). Engineering nanodisc scaffold proteins for native mass spectrometry. Anal. Chem. 89, 11189-11192.

Sanders, C.R. and Landis, G.C. (1995). Reconstitution of membrane proteins into lipid-rich bilayered mixed micelles for NMR studies. Biochemistry 34, 4030-4040.

Sanders, C.R. and Prosser, R.S. (1998). Bicelles: a model membrane system for all seasons? Structure 6,1227-1234.

Scacioc, A., Schmidt, C., Hofmann, T., Urlaub, H., Kühnel, K., and Pérez-Lara, Á. (2017). Structure based biophysical characterization of the PROPPIN Atg18 shows Atg18 oligomerization upon membrane binding. Sci. Rep. 7, 14008.

Schafer, L.V., de Jong, D.H., Holt, A., Rzepiela, A.J., de Vries, A.H., Poolman, B., Killian, J.A., and Marrink, S.J. (2011). Lipid packing drives the segregation of transmembrane helices into disordered lipid domains in model membranes. Proc. Natl. Acad. Sci. USA 108, 1343-1348.

Schmidt, C. and Robinson, C.V. (2014). A comparative cross-linking strategy to probe conformational changes in protein complexes. Nat. Protoc. 9, 2224-2236.

Schmidt, C. and Urlaub, H. (2017). Combining cryo-electron microscopy (cryo-EM) and cross-linking mass spectrometry (CXMS) for structural elucidation of large protein assemblies. Curr. Opin. Struct. Biol. 46, 157-168.

Schmidt, C., Zhou, M., Marriott, H., Morgner, N., Politis, A., and Robinson, C.V. (2013). Comparative cross-linking and mass spectrometry of an intact F-type ATPase suggest a role for phosphorylation. Nat. Commun. 4, 1985.

Schmidt, C., Macpherson, J.A., Lau, A.M., Tan, K.W., Fraternali, F., and Politis, A. (2017a). Surface accessibility and dynamics of macromolecular assemblies probed by covalent labeling mass spectrometry and integrative modeling. Anal. Chem. 89, 1459-1468.

Schmidt, C., Beilsten-Edmands, V., Mohammed, S., and Robinson, C.V. (2017b). Acetylation and phosphorylation control both local and global stability of the chloroplast F1 ATP synthase. Sci. Rep. 7, 44068.
Schnell, D.J. and Hebert, D.N. (2003). Protein translocons: multifunctional mediators of protein translocation across membranes. Cell. 112, 491-505.

Schwudke, D., Schuhmann, K., Herzog, R., Bornstein, S.R., and Shevchenko, A. (2011). Shotgun lipidomics on high resolution mass spectrometers. Cold Spring Harb. Perspect. Biol. 3, a004614.

Seddon, A.M., Curnow, P., and Booth, P.J. (2004). Membrane proteins, lipids and detergents: not just a soap opera. Biochim. Biophys. Acta 1666, 105-117.

Sharpe, H.J., Stevens, T.J., and Munro, S. (2010). A comprehensive comparison of transmembrane domains reveals organellespecific properties. Cell 142, 158-169.

Shevchenko, A. and Simons, K. (2010). Lipidomics: coming to grips with lipid diversity. Nat. Rev. Mol. Cell Biol. 11, 593-598.

Shevchenko, A., Wilm, M., Vorm, O., and Mann, M. (1996). Mass spectrometric sequencing of proteins silver-stained polyacrylamide gels. Anal. Chem. 68, 850-858.

Shinzawa-Itoh, K., Aoyama, H., Muramoto, K., Terada, H., Kurauchi, T., Tadehara, Y., Yamasaki, A., Sugimura, T., Kurono, S., Tsujimoto, K., et al. (2007). Structures and physiological roles of 13 integral lipids of bovine heart cytochrome c oxidase. EMBO J. 26, 1713-1725.

Simons, K. and Sampaio, J.L. (2011). Membrane organization and lipid rafts. Cold Spring Harb. Perspect. Biol. 3, a004697.

Sinz, A. (2014). The advancement of chemical cross-linking and mass spectrometry for structural proteomics: from single proteins to protein interaction networks. Expert Rev. Proteomics $11,733-743$.

Sinz, A. (2017). Divide and conquer: cleavable cross-linkers to study protein conformation and protein-protein interactions. Anal. Bioanal. Chem. 409, 33-44.

Sobott, F., Hernández, H., McCammon, M.G., Tito, M.A., and Robinson, C.V. (2002). A tandem mass spectrometer for improved transmission and analysis of large macromolecular assemblies. Anal. Chem. 74, 1402-1407.

Steen, H. and Mann, M. (2004). The ABCs (and XYZs) of peptide sequencing. Nat. Rev. Mol. Cell Biol. 5, 699-711.

Suchanek, M., Radzikowska, A., and Thiele, C. (2005). Photo-leucine and photo-methionine allow identification of protein-protein interactions in living cells. Nat. Methods 2, 261-267.

Taverner, T., Hernandez, H., Sharon, M., Ruotolo, B.T., Matak-Vinkovic, D., Devos, D., Russell, R.B., and Robinson, C.V. (2008). Subunit architecture of intact protein complexes from mass spectrometry and homology modeling. Acc. Chem. Res. 41, 617-627.

Thalassinos, K., Pandurangan, A.P., Xu, M., Alber, F., and Topf, M. (2013). Conformational States of macromolecular assemblies explored by integrative structure calculation. Structure 21, 1500-1508.

Tribet, C., Audebert, R., and Popot, J.L. (1996). Amphipols: polymers that keep membrane proteins soluble in aqueous solutions. Proc. Natl. Acad. Sci. USA 93, 15047-15050.

Uetrecht, C., Rose, R.J., van Duijn, E., Lorenzen, K., and Heck, A.J. (2010). Ion mobility mass spectrometry of proteins and protein assemblies. Chem. Soc. Rev. 39, 1633-1655.

van den Bogaart, G., Meyenberg, K., Risselada, H.J., Amin, H., Willig, K.I., Hubrich, B.E., Dier, M., Hell, S.W., Grubmuller, H., Diederichsen, U., et al. (2011). Membrane protein sequestering by ionic protein-lipid interactions. Nature 479, 552-555.

Walzthoeni, T., Claassen, M., Leitner, A., Herzog, F., Bohn, S., Förster, F., Beck, M., and Aebersold, R. (2012). False discovery 
rate estimation for cross-linked peptides identified by mass spectrometry. Nat. Methods 9, 901-903.

Wattenberg, A., Sobott, F., Barth, H.-D., and Brutschy, B. (2000). Studying noncovalent protein complexes in aqueous solution with laser desorption mass spectrometry. Int. J. Mass Spectrom. 203, 49-57.

Williams, P.E., Klein, D.R., Greer, S.M., and Brodbelt, J.S. (2017). Pinpointing double bond and sn-positions in glycerophospholipids via hybrid $193 \mathrm{~nm}$ ultraviolet photodissociation (UVPD) mass spectrometry. J. Am. Chem. Soc. 139, 15681-15690.

Wilm, M., Shevchenko, A., Houthaeve, T., Breit, S., Schweigerer, L., Fotsis, T., and Mann, M. (1996). Femtomole sequencing of proteins from polyacrylamide gels by nano-electrospray mass spectrometry. Nature 379, 466-469.

Wu, C.C. and Yates, J.R. (2003). The application of mass spectrometry to membrane proteomics. Nat. Biotechnol. 21, 262-267.

Xu, G. and Chance, M.R. (2007). Hydroxyl radical-mediated modification of proteins as probes for structural proteomics. Chem. Rev. 107, 3514-3543.

Yang, B., Wu, Y.-J., Zhu, M., Fan, S.-B., Lin, J., Zhang, K., Li, S., Chi, H., Li, Y.-X., Chen, H.-F., et al. (2012). Identification of cross-linked peptides from complex samples. Nat. Methods 9 , 904-906.
Yetukuri, L., Ekroos, K., Vidal-Puig, A., and Oresic, M. (2008). Informatics and computational strategies for the study of lipids. Mol. Biosyst. 4, 121-127.

Yu, C. and Huang, L. (2017). Cross-linking mass spectrometry: an emerging technology for interactomics and structural biology. Anal. Chem, 90, 144-165.

Yu, Y.-Q., Gilar, M., Lee, P.J., Bouvier, E.S.P., and Gebler, J.C. (2003). Enzyme-friendly, mass spectrometry-compatible surfactant for in-solution enzymatic digestion of proteins. Anal. Chem. 75, 6023-6028.

Zhang, H., Harrington, L.B., Lu, Y., Prado, M., Saer, R., Rempel, D., Blankenship, R.E., and Gross, M.L. (2017). Native mass spectrometry characterizes the photosynthetic reaction center complex from the purple bacterium Rhodobacter sphaeroides. J. Am. Soc. Mass Spectrom. 28, 87-95.

Zhou, Y. and Vachet, R.W. (2012). Increased protein structural resolution from diethylpyrocarbonate-based covalent labeling and mass spectrometric detection. J. Am. Soc. Mass Spectrom. 23, 708-717.

Zhou, M., Morgner, N., Barrera, N.P., Politis, A., Isaacson, S.C., Matak-Vinković, D., Murata, T., Bernal, R.A., Stock, D., and Robinson, C.V. (2011). Mass spectrometry of intact V-type ATPases reveals bound lipids and the effects of nucleotide binding. Science 334, 380-385. 